\title{
A Photochemical Two-Step Formal [5+2] Cycloaddition: A Conden- sation-Ring-Expansion Approach to Substituted Azepanes
}

\author{
Scott M. Thullen ${ }^{\mathrm{a}, \mathrm{b}}$ \\ David M. Rubush'b,c \\ Tomislav Rovis*a,b (D) \\ a Department of Chemistry, Columbia University, New York, \\ NY 10027, USA \\ tr2504@columbia.edu \\ b Department of Chemistry, Colorado State University, Fort \\ Collins, CO 80523, USA \\ ' Current Address: Department of Chemistry, Benedictine \\ University, Lisle, IL 60532, USA
}

Dedicated to our friend and colleague Victor Snieckus on the occasion of his $80^{\text {th }}$ birthday.
Received: 08.03.2017

Accepted after revision: 10.05.2017

Published online: 29.06 .2017

DOI: 10.1055/s-0036-1589049; Art ID: st-2017-b0169-I

Abstract Seven-membered nitrogen-containing heterocycles are considerably underrepresented in the literature compared to their five- and six-membered analogues. Herein, we report a relatively understudied photochemical rearrangement of $\mathrm{N}$-vinylpyrrolidinones to azepin-4ones in good yields. This transformation allows for the conversion of readily available pyrrolidinones and aldehydes to densely functionalized azepane derivatives in a facile two-step procedure.

Key words azepane, photochemistry, photo-Fries rearrangement, heterocycles, $[5+2]$ cycloaddition

Seven-membered nitrogen-containing rings present an intriguing challenge compared to their five- and six-membered analogues. Although they occur with less frequency than these other 'common' rings, their appearance in molecules of biological interest provides significant motivation to construct these frameworks efficiently and effectively. ${ }^{1}$ Additionally, five- and six-membered heterocycles have been heavily explored, while substantially less work has been done on the construction of seven-membered (and larger) nitrogen-containing rings (Figure 1$){ }^{2}$

This is particularly evident when considering the incidence of seven- and eight-membered rings in pharmaceuticals approved by the FDA ${ }^{3}$ compared to their coverage in the patent literature (Figure 1$){ }^{4}$

While cyclization strategies dominate azepane and azocane synthesis, we felt that two component-coupling approaches were fundamentally more powerful and considered various disconnections. A [5+2] approach proved alluring since the two-atom unit may be an alkene or surrogate, trivially accessed and abundant, while the five-atom unit is pyrrolidinone. Such a union could be realized by condensa-
24 Examples 40-92\% Yield
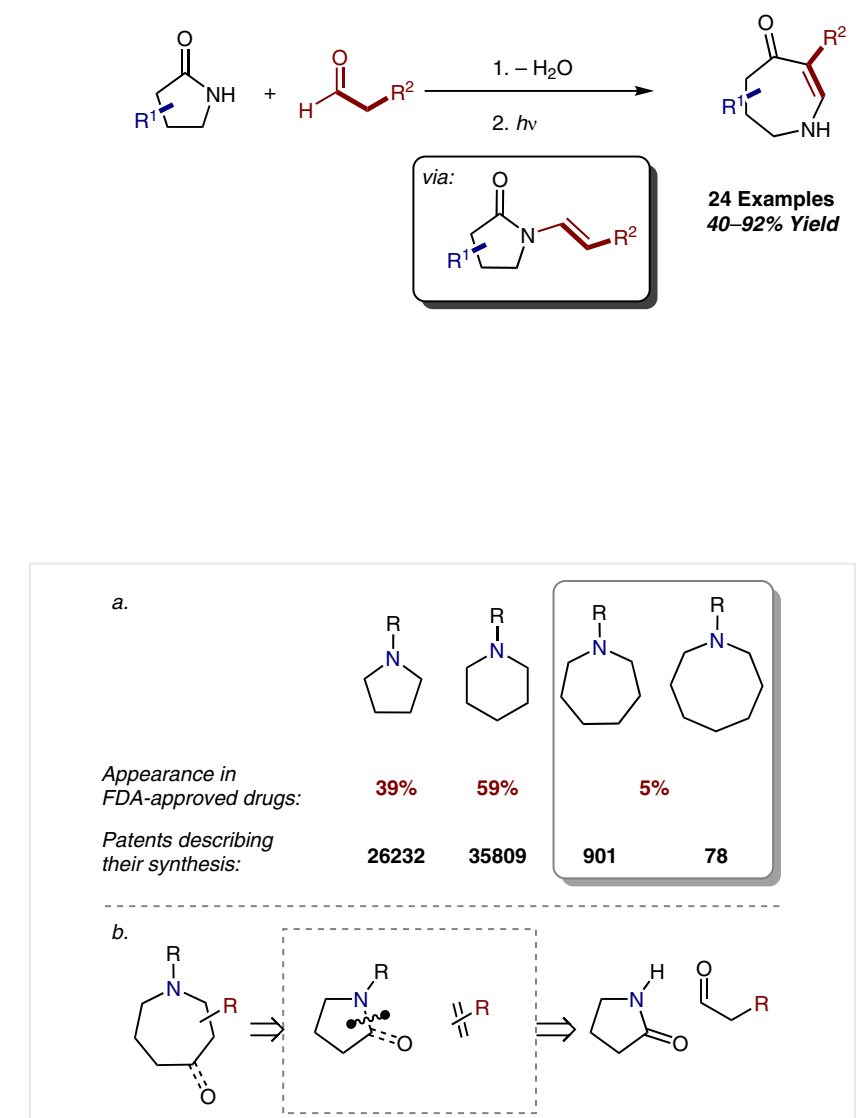

Figure 1 a. Prevalence of saturated nitrogen-containing heterocycles in FDA-approved pharmaceuticals $(\%)^{3}$ and in patents detailing their construction; ${ }^{4}$ b. A conceptualized approach at a formal $[5+2]$ union to form azepanes.

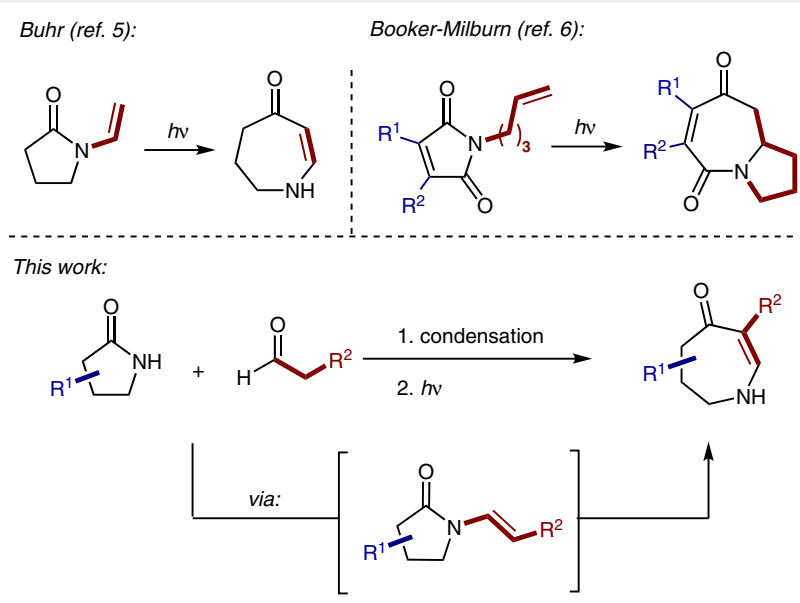

Scheme 1 Comparison between this work and prior art 
tion of pyrrolidinone with aldehydes followed by a photochemical Fries-like rearrangement to form the azepinone. This reaction was first described in the patent literature (Scheme 1); $;^{5}$ subsequent studies by Booker-Milburn ${ }^{6}$, Mazzocchi $^{7}$, and others ${ }^{8}$ have shown similar photochemical [5+2]-ring-expansion chemistry with the maleimide and phthalimide frameworks, respectively. Stimulated by the conviction that this photo-Fries-like chemistry ${ }^{9}$ could be a powerful reaction for the synthesis of azepanes, we sought to develop the method.

The $N$-vinylpyrrolidinones are readily accessible through the condensation of a desired aldehyde and pyrrolidinone (Scheme 2). Unlike the chemistry of the maleimides, this method allows for the facile and diverse structural modification and functionalization around the azepane motif. Additionally, the resultant vinylogous amide moiety formed during the reaction is an exemplary functional group for further manipulation. ${ }^{10}$

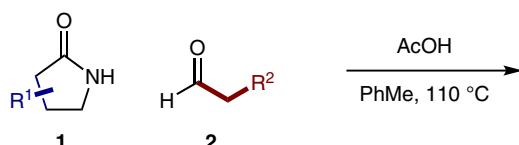

Scheme 2 Formation of $N$-vinylpyrrolidinones

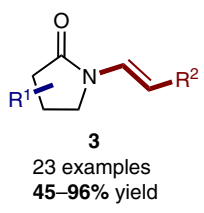

$45-96 \%$ yield

Our investigation into the photochemical ${ }^{11}[5+2]$ cycloaddition began with optimization of the reaction conditions on 3a, using the conditions reported in the patent literature $^{5}$ as a starting point (Table 1 , entry 1 ). The use of THF as solvent increases the yield of the reaction to $48 \%$ over 24 hours (Table 1, entry 8). Dilution of the reaction to $0.02 \mathrm{M}$ further increases the yield, presumably due to disfavored competitive polymerization $^{12}$ and dimerization ${ }^{13}$ pathways.

Table 1 Optimization Conditions

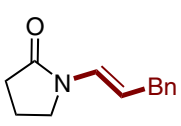

3a

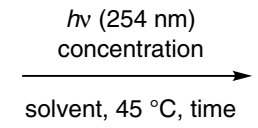

solvent, $45^{\circ} \mathrm{C}$, time

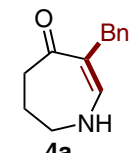

$4 a$

\begin{tabular}{lllll}
\hline Entry & Solvent & Concentration (M) & Time (h) & Yield (\%) \\
\hline 1 & MeOH & 0.2 & 24 & 40 \\
2 & MeCN & 0.2 & 24 & 22 \\
3 & THF & 0.2 & 24 & 48 \\
4 & THF & 0.2 & 48 & 75 \\
5 & THF & 0.5 & 48 & 67 \\
6 & THF & 1.0 & 48 & 55 \\
7 & THF & 0.1 & 48 & 81 \\
8 & THF & 0.02 & 48 & 92 \\
\hline
\end{tabular}

The photochemical rearrangement tolerates a broad range of substitution on the enamine (Scheme 3) including simple alkyl groups (4c-e) as well as aryl (4f), and electronrich and electron-poor benzyl substituents (4m-o). Dienamine-substituted pyrrolidinone $\mathbf{3 1}$ participates in the reaction, although in diminished yield. A stereocenter present on the alkene substituent remains intact over the course of the reaction $(\mathbf{4 j})$. Unfortunately, efforts to create quaternary centers $\alpha$ to the ketone as well as substrates which included carbonyl moieties other than the reactive amide showed no conversion under the irradiative conditions. ${ }^{14}$
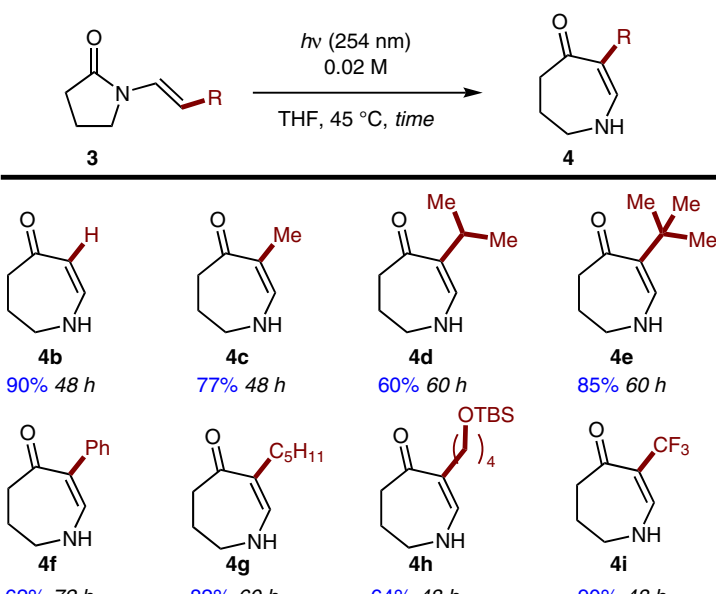

$62 \% 72 h$

$82 \% 60 h$

$64 \% 48 h$

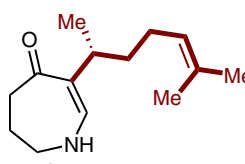

4j

$58 \%, 99 \%$ ee $48 h^{\star}$

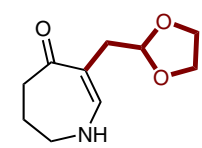

$4 \mathbf{k}$

$85 \% 48 h$

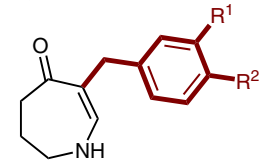

$$
\begin{aligned}
& \mathrm{R}^{1}, \mathrm{R}^{2}=\mathrm{H}, \mathrm{H} \quad=92 \% 48 h(4 \mathrm{a}) \\
& \mathrm{H}, \mathrm{OMe}=74 \% 48 \mathrm{~h}(4 \mathrm{~m}) \\
& \mathrm{H}, \mathrm{CF}_{3}=72 \% 48 h(4 \mathrm{n}) \\
& \mathrm{OMe}, \mathrm{OMe}=74 \% 48 h(40)
\end{aligned}
$$
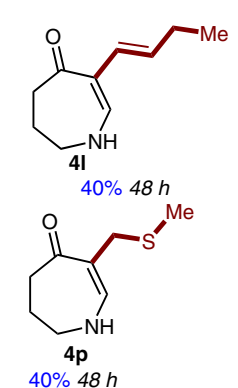

* $>99 \%$ ee 3 used as starting material.

Scheme 3 Scope of alkene substituent

Functionalization at any of the positions on the pyrrolidinone ring is also possible (Scheme 4). Interestingly, heteroatoms are often tolerated, even in the case of unprotected alcohols. Pre-existing stereocenters on the pyrrolidinone ring do not racemize in the rearrangement chemistry with the exception of stereocenters $\alpha$ to the amide. It is presumed that this is due to the Norrish Type I cleavage of the $\mathrm{C}-\mathrm{C}$ bond that does not lead to any productive pathways and recombines, scrambling the stereocenter. 


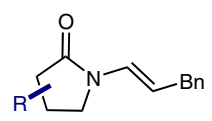

5

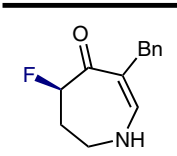

$6 a$

$65 \%, 6 \% \mathrm{ee}^{*}$<smiles>CC(C)(C)OC[C@H]1CCC(=O)C(Cc2ccccc2)=CN1</smiles>

$6 d$
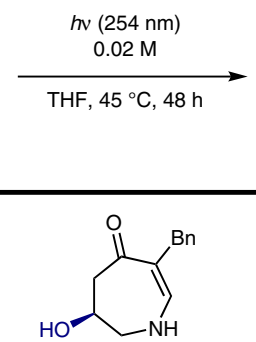

6b

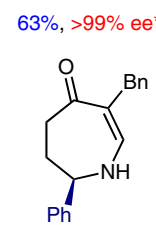

$6 e$

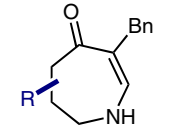

6

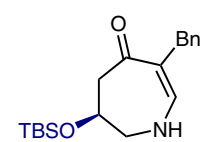

$6 c$
$89 \%,>99 \% \mathrm{ee}^{*}$ $51 \%,>99 \% \mathrm{ee}^{\star}$

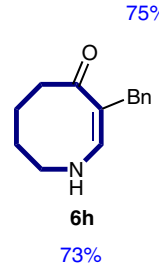

${ }^{*}>99 \%$ ee $\mathbf{5}$ used as starting material.

Scheme 4 Scope of pyrrolidinone substituent

The transformation also allows us to access larger rings (6h). A further increase in ring size leads to difficulty in purification due to competitive polymerization, despite diluting the samples to $0.001 \mathrm{M}$.

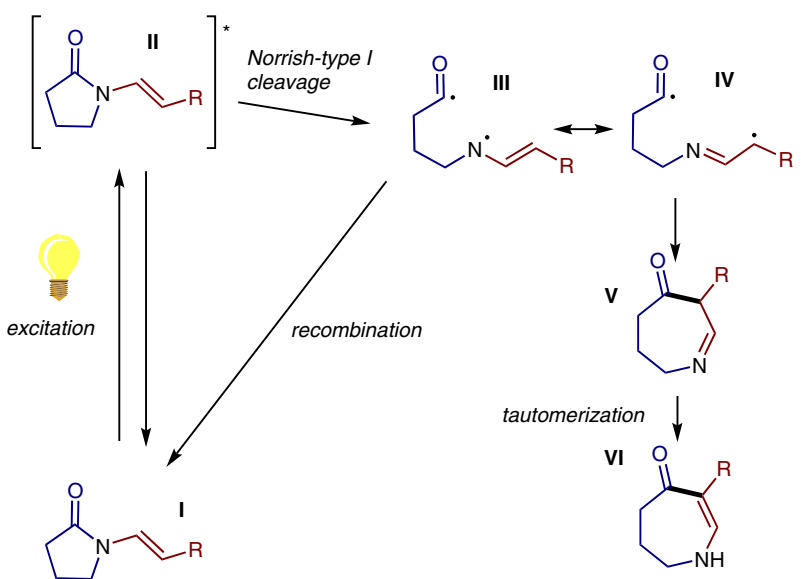

Scheme 5 Potential reaction mechanism ${ }^{15}$

A potential mechanism for this reactivity, as argued by Shizuka and coworkers ${ }^{15}$, involves the Norrish-type I $(\alpha)$ homolytic cleavage of the amide bond after irradiation with $254 \mathrm{~nm}$ light (Scheme 5). The resultant biradical III can then either recombine to reform the starting material or combine with the carbon $\beta$ to the nitrogen to generate imine $\mathbf{V}$. Tautomerization of $\mathbf{V}$ gives the observed product. Investigation of a similar maleimide system by BookerMilburn and coworkers ${ }^{6 c}$ suggests that the reactive biradical intermediate proceeds through an excited singlet state as opposed to an excited triplet state. When directly irradiated, they solely observed the [5+2] cycloaddition product whereas when they irradiated the maleimide in the presence of the triplet sensitizer benzophenone, they solely observed the [2+2] cycloaddition between the alkene and maleimide backbone. ${ }^{16}$ In our system, addition of oxygen or catalytic benzophenone as triplet quenchers did not interfere with the outcome of the reaction, supporting the likelihood of a singlet pathway.

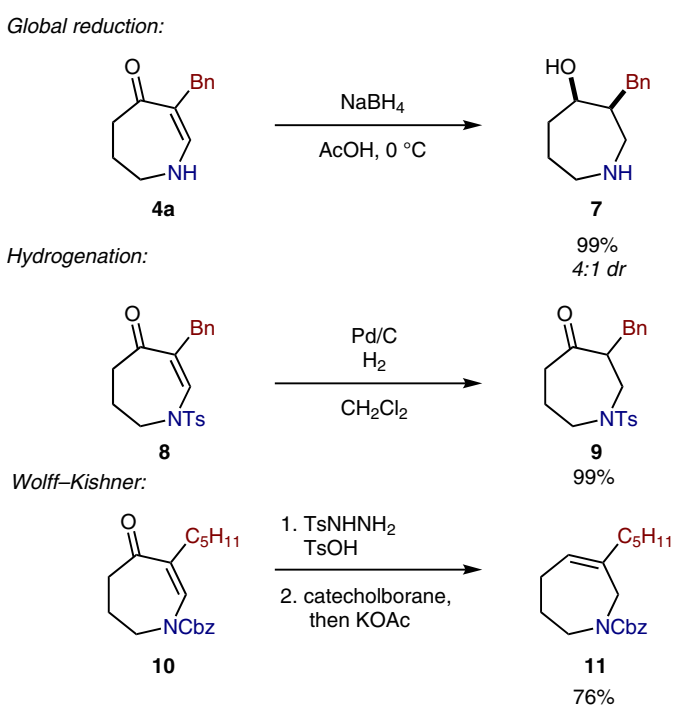

Scheme 6 Derivatization reactions

The cyclic vinylogous amide moiety formed in this transformation is easily manipulated to a variety of useful functional handles (Scheme 6). Georg ${ }^{10}$ and others ${ }^{17}$ have extensively studied the modification of the six-membered vinylogous amide analogues; however, the comparable reactivity with seven-membered azepin-4-ones is relatively rare. ${ }^{18}$ We found that these scaffolds easily convert into other useful seven-membered heterocycles. Global reduction of the vinylogous amide, as well as semireduction by hydrogenation to the ketone each proceed uneventfully; a WolffKishner protocol results in deoxygenation with alkene migration to deliver 11.

In conclusion, we have developed a formal two-step [5+2] cycloaddition to form azepinones exploiting a relatively understudied photochemical rearrangement. ${ }^{19,20}$ This facile approach allows for the construction of synthetically useful functionalized azepin-4-ones in good yields from 
readily available aldehydes and pyrrolidinones. Modification of these substrates allows for the access to a diverse set of substituted azepane derivatives.

\section{Funding Information}

We thank NIGMS for support (GM80442)

\section{Supporting Information}

Supporting information for this article is available online at https://doi.org /10.1055/s-0036-1589049.

\section{References and Notes}

(1) (a) Riley, D. L.; van Otterlo, W. A. L. Heterocycles in Natural Product Synthesis 2011, 537. (b) Greger, H. Planta Med. 2006, 72, 99.

(2) (a) Rousseau, G.; Homsi, F. Chem. Soc. Rev. 1997, 26, 453. (b) Illuminati, G.; Mandolini, L. Acc. Chem. Res. 1981, 14, 87.

(3) (a) Vitaku, E.; Smith, B. R.; Njardarson, J. T. J. Med. Chem. 2014, 57, 10257. (b) Smith, B. R.; Eastman, C. M.; Njardarson, J. T. J. Med. Chem. 2014, 57, 9764. (c) Ilardi, E. A.; Vitaku, E.; Njardarson, J. T. J. Med. Chem. 2014, 57, 2832.

(4) Based on Scifinder search of patents containing synthesis of 'pyrrolidines', 'piperidines', 'azepanes', and 'azocanes'.

(5) Buhr, G. DE 2013761, 1970.

(6) (a) Booker-Milburn, K. I.; Anson, C. E.; Clissold, C.; Costin, N. J.; Dainty, R. F.; Murray, M.; Patel, D.; Sharpe, A. Eur. J. Org. Chem. 2001, 1473. (b) Booker-Milburn, K. I.; Dudin, L. F.; Anson, C. E.; Guile, S. D. Org. Lett. 2001, 3, 3005. (c) Roscini, C.; Cubbage, K. L.; Berry, M.; Orr-Ewing, A. J.; Booker-Milburn, K. I. Angew. Chem. Int. Ed. 2009, 48, 8716. (d) Cubbage, K. L.; Orr-Ewing, A. J.; Booker-Milburn, K. I. Angew. Chem. Int. Ed. 2009, 48, 2514. (e) Lainchbury, M. D.; Medley, M. I.; Taylor, P. M.; Hirst, P.; Dohle, W.; Booker-Milburn, K. I. J. Org. Chem. 2008, 73, 6497.

(7) (a) Mazzocchi, P. H.; Bowen, M. J.; Narain, N. K. J. Am. Chem. Soc. 1977, 99, 7063. (b) Mazzocchi, P. H.; Minamikawa, S.; Bowen, M. J. J. Org. Chem. 1978, 43, 3079. (c) Mazzocchi, P. H.; Wilson, P.; Khachik, F.; Klinger, L.; Minamikawa, S. J. Org. Chem. 1983, 48, 2981.

(8) Sato, Y.; Nakai, H.; Mizoguchi, T.; Hatanaka, Y.; Kanaoka, Y. J. Am. Chem. Soc. 1976, 98, 2349.

(9) For the seminal work on amide photo-Fries chemistry, see: (a) Izzo, P. T.; Kende, A. S. Tetrahedron Lett. 1966, 5731. (b) Yang, N. C.; Lenz, G. R. Tetrahedron Lett. 1967, 4897. (c) Hoffmann, R. W.; Eicken, K. R. Tetrahedron Lett. 1968, 1759. (d) Hoffmann, R. W.; Eicken, K. R. Chem. Ber. 1969, 102, 2987.

(10) For a recent review on the reactivity of cyclic vinylogous amides as well as other applicable references, see: Seki, H.; Georg, G. I. Synlett 2014, 25, 2536.

(11) For recent reviews on photochemistry in organic synthesis, see: (a) Tanoury, G. J. Synthesis 2016, 48, 2009. (b) Hoffmann, N. Chem. Rev. 2008, 108, 1052.
(12) (a) Haaf, F.; Sanner, A.; Straub, F. Polym. J. 1985, 17, 143. (b) Güven, O.; Șen, M. Polymer 1991, 32, 2491. (c) Yamago, S. Chem. Rev. 2009, 109, 5051.

(13) Song, F.; Snook, J. H.; Foxman, B. M.; Snider, B. B. Tetrahedron 1998, 54, 13035.

(14) Compounds that do not show reactivity in the photochemical rearrangement chemistry are listed in the Supporting Information. Generally speaking, other carbonyl moieties or other UVreactive moieties seem to be detrimental to the reaction.

(15) Shizuka, H.; Ogiwara, T.; Morita, T. Bull. Chem. Soc. Jpn. 1977, 50, 2067.

(16) Specifically (from ref. 6c) see Scheme 7.

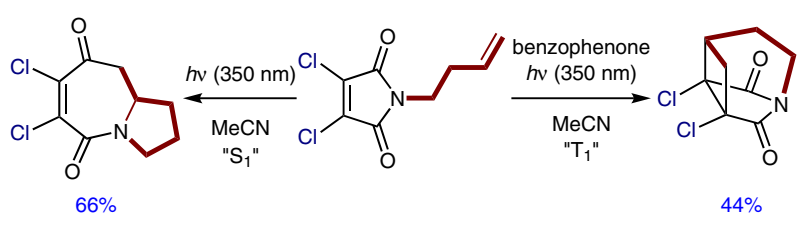

Scheme 7

(17) For select approaches to derivatize six-membered ring vinylogous amides, see: (a) Hickmott, P. W. Tetrahedron 1982, 38, 1975. (b) Comins, D. L.; Zeller, E. Tetrahedron Lett. 1991, 32, 5889. (c) Sěbesta, R.; Pizzuti, M. G.; Boersma, A. J.; Minnaard, A. J.; Feringa, B. L. Chem. Commun. 2005, 13, 1711. (d) Seki, H.; Georg, G. I. J. Am. Chem. Soc. 2010, 132, 15512. (e) Brimouille, R.; Bach, T. Science 2013, 342, 840.

(18) (a) Granger, B. A.; Jewett, I. T.; Butler, J. D.; Hua, B.; Knezevic, C. E.; Parkinson, E. I.; Hergenrother, P. J.; Martin, S. F. J. Am. Chem. Soc. 2013, 135, 12984. (b) Granger, B. A.; Jewett, I. T.; Butler, J. D.; Martin, S. F. Tetrahedron 2014, 70, 4094. (c) Sakya, S. M.; Flick, A. C.; Coe, J. W.; Gray, D. L.; Liang, S.; Ferri, F.; Van Den Berg, M.; Pouwer, K. Tetrahedron Lett. 2012, 53, 723.

(19) General Procedure An $\mathrm{N}$-vinyl pyrrolidinone was charged in a quartz reaction vessel, under an argon atmosphere, and degassed THF was added $(0.01 \mathrm{M})$ via cannula. The quartz reaction vessel was irradiated in a Rayonet reactor (internal temp. ca. $45^{\circ} \mathrm{C}$ ) using 254 $\mathrm{nm}$ mercury arc lamps until completion. The reaction was then passed through a short silica plug and concentrated in vacuo. The crude product was purified using flash chromatography on silica gel (EtOAc-hexanes or $\mathrm{MeOH}-\mathrm{CH}_{2} \mathrm{Cl}_{2}$ ).

(20) Representative Product 3-Benzyl-1,5,6,7-tetrahydro-4Hazepin-4-one (4a)

Compound 4a was obtained using general procedure from vinyl lactam 3a. White solid; 92\% yield. ${ }^{1} \mathrm{H} \mathrm{NMR}\left(400 \mathrm{MHz}, \mathrm{CDCl}_{3}\right)$ : $\delta=7.31-7.08(\mathrm{~m}, 5 \mathrm{H}), 6.76(\mathrm{~d}, J=7.3 \mathrm{~Hz}, 1 \mathrm{H}), 5.61(\mathrm{~s}, 1 \mathrm{H}), 3.53$ (s, $2 \mathrm{H}), 3.46-3.36(\mathrm{~m}, 2 \mathrm{H}), 2.78-2.68(\mathrm{~m}, 2 \mathrm{H}), 1.99(\mathrm{~m}, 2 \mathrm{H}) .{ }^{13} \mathrm{C}$ NMR (101 MHz, $\left.\mathrm{CDCl}_{3}\right): \delta=198.76,142.55,128.61,128.17$, 125.60, 109.74, 47.18, 42.62, 37.00, 22.94. IR (ATR): 3278, 3075, 2929, 1617, 1544, 1405, 1367, 1325, 1234, 1159, 1108, 1066 $\mathrm{cm}^{-1} . R_{f}=0.15$ (85:15 EtOAc-hexanes). LRMS (ESI+APCI): $\mathrm{m} / \mathrm{z}$ $[\mathrm{M}+\mathrm{H}]^{+}$calcd for $\left[\mathrm{C}_{13} \mathrm{H}_{16} \mathrm{NO}\right]^{+}:$202.28; found: 202.4 . 